\title{
Cuidado em Heidegger: uma possibilidade ontológica para a enfermagem*
}

\author{
Care in Heidegger: an ontological possibility for nursing \\ Cuidado en Heidegger: una posibilidad ontológica para la enfermería
}
Marília de Fátima Vieira de Oliveira', Telma Elisa Carraro'
'Universidade Federal de Santa Catarina. Departamento de Enfermagem. Programa de Pós-graduação em Enfermagem. Florianópolis, SC

Submissão: 01/02/2010

Aprovação: $27 / 07 / 2010$

\section{RESUMO}

Tendo em vista as dimensões Que envolvem o cuidado humano, este trabalho teve como objetivo apresentar reflexões sobre o cuidado de enfermagem eneuanto possibilidade ontológica. Em Heidegger consideramos os conceitos Que permeiam o fundamento de seu pensamento. Estas reflexões oferecem recurso teórico Que permitem o reconhecimento de Que conviver no cotidiano de ações da enfermagem é um desafio que nos remete a um novo olhar para a magnitude do cuidado. Porém, as ações de cuidado não devem se direcionar somente para o prisma deste filósofo, mas conviver com esse pensamento na busca de reflexão, e encontro, perscrutando tudo aQuilo Que possa contribuir para um cuidado de enfermagem compromissado com o bem, com a ética, e com o respeito ao outro.

Descritores: Cuidado; Enfermagem; Filosofia em enfermagem.

\section{ABSTRACT}

Given the dimensions involving human care, this study aimed at providing a reflection on nursing care as an ontological possibility. In Heidegger we consider the concepts that underlie the foundation of his thought. These reflections offer theoretical resource that allows the recognition that live in the everyday actions of nursing is a challenge that leads us to a new look at the magnitude of care. However, the actions of care should not target only the perspective of a philosopher, but live with that thought in search of reflection, and find, scrutinizing everything you contribute to a nursing care committed to the right, with ethics, and with respect for others.

Key words: Care; Nursing; Philosophy in nursing.

\section{RESUMEN}

Dadas las dimensiones Que involucra la atención humana, este estudio tiene como objetivo facilitar la reflexión sobre el cuidado de enfermería como posibilidad ontológica. En Heidegger consideramos los conceptos que subyacen en la base de su pensamiento. Estas reflexiones teóricas de oferta de recursos que permite el reconocimiento de que vivimos en las acciones cotidianas de la enfermería es un reto Que nos conduce a una nueva mirada a la magnitud de la atención. Sin embargo, las acciones de la atención no debe dirigirse sólo la perspectiva de un filósofo, pero vivir con ese pensamiento en la búsqueda de la reflexión, y encontrar, escrutando todo lo Que contribuyen a una atención de enfermería comprometido con el derecho con ética, y con el respeto por los demás.

Descriptores: Cuidado; Enfermería; Filosofía en enfermería. 


\section{INTRODUÇÃO}

Cada vez mais as ações e relações humanas estão impregnadas pela razão onde a natureza não mais se harmoniza com o homem, onde o cuidado humano vem ao encontro de uma realidade de vida acelerada, complexa e transitória Que o mundo moderno vivencia.

Sobre essas relações Que vivemos, podemos chamá-las de efemeridade moderna Que formam dessa maneira o mundo do Que está disponível ${ }^{(1)}$. E é revelado que Heidegger tenta salvar o mundo do disponível para o pensar, porque em geral ele é visto com excessiva pressa pelo conhecimento filosófico ${ }^{(2)}$. As coisas são organizadas de maneira apressada de modo Que só existam de maneira indiferente. E mais tarde isso vai ocasionar no Que se chama de esquecimento-do-ser ${ }^{(1)}$.

No meio dessa celeridade demasiada a saúde, o cuidado, as pessoas Que são cuidadas como também as Que cuidam sofrem as conseQüências da indiferença. O conhecimento entra no mundo das especializações e o pensamento nos parece fracionado o Que nos leva a compreender os acontecimentos da vida limitadamente.

Deste modo, o Que nos parece é que estamos no meio de múltiplas visões de mundo tentando explicar como fazer e assim "há uma tendência de afirmar Que nossa realidade carece de unidade de sentido Que possa ser abarcada por alguma reflexão. Insiste-se na fragmentação Que torna ininteligíveis as pretensões universais. Além da falta de sentido, está o não-sentido. A sociedade contemporânea, em acelerado processo de mudança, está dispersa e desprovida de referenciais. Há um vácuo racional e ontológico fundamental"(3).

Logo, sustentamos dizer Que vivemos numa atmosfera de desconforto com os imediatismos da vida moderna Que nos remete para a falta de compromisso moral com o outro, o determinismo pela tecnologia e pela técnica e ainda a fluidez nas relações de cuidado. Enfim, o mundo está aí, posto entre os vários fenômenos Que se apresentam para nós enquanto seres humanos.

Assim, entendemos Que essa conseQüência também se estende ao fenômeno do cuidado, pois se pensarmos nele como a essência da enfermagem, devemos nos perguntar: Qual o sentido desse cuidado no mundo de hoje? Qual o sentido das práticas de saúde em enfermagem? Qual a dimensão Que o cuidado de enfermagem ocupa?

Se pararmos para fazer essas reflexões, talvez possamos compreender Que aQuilo Que diz respeito às nossas atitudes enQuanto cuidadores precisa estar sendo diariamente pensada e avaliada na rotina da prática de enfermagem. Pois, o cuidado enQuanto ato, está presente todos os dias Quando realizamos procedimentos, Quando cumprimos tarefas, Quando realizamos diagnósticos, Quando manipulamos um equipamento ou Quando administramos um medicamento, mas é este mesmo cuidado Que precisa ser reconhecido na perspectiva ontológica de sua existência.

Assim se solicita a criação de uma atmosfera de benQuerença, de cuidado, de amizade, e de amor tal Que transforma os conflitos em tensões dinâmicas, a competição em emulação saudável e as divergências em oportunidade para convergências na adversidade ${ }^{(4)}$.

Por tudo isso é preciso estar atento, é importante correr o risco de errar e entrar no que se chama de "jogo", ou seja, lançar-se no mundo e ir ao encontro das inúmeras possibilidades Que ele oferece. Mas para Que esse encontro aconteça é preciso observar cuida- dosamente o mundo-em torno ${ }^{(2)}$.

Olhar o Que está em torno é visualizar o que não está visível ou palpável, é também admitir Que os fenômenos em saúde revelam a capacidade de abrangência das experiências humanas, o que de fato dá sentido à nossa vivência.

Sobre essa atenção traz-se um exemplo em Heidegger "Não percebo como uma tábua laqueada a Que eu habitualmente abro. Quando estou familiarizado com ela, nem a percebo. Eu a abro para ir ao meu escritório. Ela tem seu 'lugar' no meu espaço vital, mas também no meu tempo vital: ela desempenha determinado papel no ritual de meu cotidiano. Seu ranger faz parte dele, os rastros de seu uso, as lembranças que se prendem nela, etc. Essa porta segundo a expressão de Heidegger está disponível (zuhanden). Se caso alguma vez, surpreendentemente, ela estiver trancada e eu bater com a cabeça nela, perceberei doloridamente a porta como tábua dura Que ela realmente é. Então a porta disponível (zuhanden) se tornará uma porta simplesmente existente (vorhanden)"(2).

Esse talvez seja um dos espaços para acontecimentos importantes no mundo do cuidado de enfermagem. Nossas relações de cuidado vivenciadas todos os dias adeuirem um caráter de familiaridade Que passamos a conviver em espaços e com os outros sem perceber os detalhes Que ali acontecem. Precisamos pensar cuidadosamente sobre esse cuidado.

Portanto, na perspectiva de contribuir para a construção ontológica do cuidado de enfermagem, fomos buscar em Heidegger algumas de suas idéias sobre cuidado presentes no § 41 de Ser e Tempo intitulado: O ser da presença como cura, Que para Heidegger é o dispositivo fundamental desse lidar com o mundo; é o Que ele chama de preocupação, onde fala da apreensão ontológica do todo estrutural. Mas antes é preciso conhecer um pouco da trajetória deste pensador.

\section{A VIDA E O PENSAMENTO DE HEIDEGGER}

Com o objetivo de refletir teoricamente sobre o cuidado de enfermagem enquanto possibilidade ontológica buscamos fundamentação em alguns conceitos centrais acerca da ontologia heideggeriana.

Martin Heidegger (1889-1976) foi um filósofo Que representou o pensamento alemão do Século $X X$, numa linha de pensamento Que podemos chamar de "corrente ontologista", Que se propõe à descentralização da hegemonia da filosofia européia. Foi um dos mais influentes pensadores deste século.

Heidegger teve toda sua formação universitária num contexto de "agitação intelectual", em um momento de reação contra o difuso pensamento positivista, Alemanha de 1870. Este momento histórico, vivenciado por ele, retrata um momento da crítica da racionalidade científica, crítica da defensiva da experiência vital e psíeuica do ser humano reconhecendo o conhecimento como via extra-racional da realidade. O fundo teológico foi o início de sua formação acadêmica profissional. Teve uma sólida educação religiosa, realizou estudos humanísticos e em 1909 iniciou a carreira eclesiástica, matriculando-se na Faculdade de Teologia na cidade de Friburgo ${ }^{(5)}$.

Porém, Heidegger não dá continuidade à carreira religiosa e em 1919 rompe com o sistema do catolicismo e em 1920 já é assistente de Husserl em Freiburg. E, filosoficamente traz de longe seus 
embasamentos teóricos por meio de Heráclito, Aristóteles, Platão, Kant, tratando-os "como se fossem seus contemporâneos, chegou tão perto deles Que escutou o Que não chegaram a dizer e colocou isso em linguagem"(6).

O cenário descrito é importante para entendermos a formação intelectual e o posicionamento do filósofo enQuanto forma de ver o mundo, pois apesar de ter a teologia como fundamento de seus estudos, fixou-se na filosofia.

Na Universidade de Freiburg, Heidegger convive num ambiente liberal cultivando os estudos históricos. Durante a guerra de 1914 ele inicia sua carreira de professor e dezenove anos depois ele assume a reitoria desta mesma universidade. Hoje é um dos ícones de referência à filosofia moderna, onde sua obra Ser e Tempo se desponta dentre um dos seus mais marcantes registros na busca do sentido do ser, pois nesta obra Heidegger "pretende representar a recolocação dos problemas fundamentais da filosofia Que é a Questão do Ser”(5).

O filosofar heideggeriano é uma constante interrogação a este respeito. Através de sua obra Ser e Tempo, Heidegger aborda a Questão do Ser através do método fenomenológico, fazendo da reflexão acerca do Ser seu ponto de partida. Este autor aponta o fato de Que, através do próprio homem, é Que se dá o caminho para se conhecer o Ser. O homem em sua solidão interroga-se sobre si mesmo, colocando-se em Questão e refletindo sobre ele mesmo, e neste momento o Ser dá-se a conhecer. O objetivo da reflexão filosófica encontrase no fato de que o filósofo, partindo da existência humana (Dasein ser-aí), procura desvendar o ser em si-mesmo"(5).

Desta forma, com o destaque da obra Ser e Tempo no mundo da filosofia moderna, Heidegger desenvolveu uma maneira particular de pensar as coisas do mundo. E indagar, não responder era a paixão de Heidegger. A isso, sobre o Que indagava e por Que procurava ele chamou-o de ser. Durante toda sua vida filosófica sempre indagou pelo ser. O sentido dessa indagação é apenas devolver à vida o mistério Que ameaça desaparecer da modernidade ${ }^{(2)}$.

\section{CONCEITOS EM HEIDEGGER}

O estilo de pensamento e a linguagem deste filósofo é algo peculiar e em seus escritos, Heidegger cria um modo único de se expressar e definir situações no mundo. Neste sentido, é necessário apresentar alguns conceitos importantes que constroem a base do pensamento do autor. Na obra Ser e Tempo, estes conceitos permeiam o fundamento de seu pensamento e trazem consigo um grande teor de significados imbricados.

Neste momento, trazemos a conhecimento apenas alguns desses conceitos em Heidegger, os Quais consideramos ser importantes para a reflexão Que nos propomos a fazer sobre o cuidado. São eles:

Dasein: é ser-aí, é pre-sença, é a maneira de dizer Que o ser só é alguma coisa a partir dos modos como ele se manifesta. Para Heidegger esse conceito representa a ênfase à idéia de Que o ser não é sem suas formas de manifestação.

Pre-sença: a pre-sença é o homem e sua relação com o mundo, ela é determinada na cotidianidade pelo seu modo de ser, é ela Que enuncia o que o mundo é. Em Ser e Tempo, a pre-sença ocupa um significado de estar lançado, jogado no tempo, se relacionar com o mundo segundo um modo de ser.

Existência: é a dimensão do existente enQuanto se reconhece jogado na temporalidade e necessariamente tendo que agir para fora de si mesmo. Esse caráter de lançar-se para fora é que dá ao humano a condição de existente.

Ser-no-mundo: é a condição do existente enQuanto consciente de sua presença no tempo e no mundo. Significa Que o homem nunca é uma subjetividade em si mesmo, senão na inter-relação com os outros e com as coisas.

Estar-no-mundo: significa o ente lançado na temporalidade, submetido a todas as nuances e todas as limitações desta condição.

Autenticidade: está relacionado com o ser- próprio. É o ser Que assume propriamente a sua existência, levando-a a um grau de responsabilidade por todos os modos de realização de sua presença na temporalidade.

Inautenticidade: é o impessoal dentro das dimensões da temporalidade e da historicidade. Heidegger fala Que nas ocupações com o mundo circundante, os outros nos vêm ao encontro naquilo Que são. É o ser existente Que ainda não chama para si a responsabilidade de assumir por si mesmo a sua presença no mundo.

Cura: refere-se a uma das características ontológicas do ser-aí e diz respeito à condição do ser-aí cuidar, zelar, por suas possibilidades de poder-ser. Do ponto de vista ôntico, todos os comportamentos e atitudes do homem são dotados de cura e guiados por uma "dedicação".

Cuidado: o cuidado pode ser entendido como ato, o Qual ocupa um sentido ôntico, ou como possibilidades, um sentido Que vai além do ato, além do Que se pode perceber, ocupando um sentido ontológico. Para Heidegger o cuidado contempla o modo positivo de cuidar dos entes, não é sinônimo de bondade, é entender autenticamente o Que é importante.

Ôntico: é tudo que é percebido, entendido, conhecido de imediato. É a compreensão cotidiana do ser em Que nos movemos. É a dimensão do ser-aí envolvido na cotidianidade.

Ontológico: a dimensão ontológica diz respeito aquilo que antecede originariamente toda manifestação ôntica e lhe garante um sentido. Diz respeito às diferentes possibilidades de ação do seraí junto às coisas e aos outros, não no sentido daQuilo que é manifesto, mas daquilo que possibilita toda manifestação.

Propriedade: caracteriza-se pelo modo de ser autêntico da existência, referindo-se contrariamente àQuilo Que diz respeito à impropriedade.

Impropriedade: é o modo de ser comum do homem, é o impessoal, o impróprio. É existir naquilo que já está estabelecido, é viver cotidianamente no modo de ser não si mesmo, é o lugar onde nós estamos. Mas não podemos descartar essa condição, pois Heidegger ressalta Que sob essas condições também o ser-aí se organiza no seu co-existir junto aos outros e às coisas.

A originalidade denota o Que é próprio em Heidegger e no sentido de considerar essa autenticidade Que repensamos a cada dia sobre o cuidado de enfermagem não como um cuidado Que se aprenda por meio de manuais e rotinas estáticas, mas um cuidado reflexivo Que considere o outro, as coisas presentes e ausentes no cotidiano, Que pense no agora já modificado, ou seja, um cuidado próprio, dinâmico e inacabado.

\section{REFLEXÕES SOBRE A ONTOLOGIA DO CUIDADO EM HEIDEGGER}

Por convivermos com desafios diários junto às estruturas de 
saúde como também por aQuilo Que impele nossas ações como ser racional Que cuida de gente existem situações Que não podem deixar de ser consideradas Quando falamos em cuidado de enfermagem. Assim, em seus constructos, Heidegger demonstra uma relação do homem consigo mesmo, aQuilo Que constitui o núcleo da existência humana como uma única realidade. É o homem como sujeito de sua própria realização.

A pre-sença é um ente Que, sendo, já está em jogo seu próprio ser. Na constituição ontológica da compreensão, o "estar em jogo" evidenciou-se como o ser Que se projeta para o poder-ser mais próprio $^{(1)}$. Desta forma, entendemos Que o homem também se relaciona, se lança, estabelece relações, sendo na maioria das vezes absorvido, toma a forma do seu mundo, da realidade eue está vivendo.

No sentido unificador e em sua densa manifestação diante da vida, Heidegger cita a concepção de cuidado euando fala da confirmação da interpretação existencial da pre-sença como cura a partir da própria interpretação pré-ontológica da pre-sença: "o cuidado encerra o 'si-mesmo' na unidade de uma estrutura, Que tanto possibilita a coneuista do Dasein ao ganhar-se, Quanto a sua perda, envolvido pelos entes intra-mundanos entre os Quais se encontra [...]. A condição existencial de possibilidade de 'cuidado com a vida' e 'dedicação' deve ser concebida como cura num sentido originário, ou seja, ontológico"(2).

AQui compreendemos Que não é possível pensar o cuidado como apenas teorização sobre a ação, como também não se pode definilo como uma simples e única estrutura em si mesma, pois sua condição mostra uma articulação estrutural Que se exprime de forma imanente. Neste sentido "nos chamam atenção para um mundo de constantes mudanças onde o exercício do cuidar deve considerar o estado permanente de desenvolvimento pessoal, de transformações e de vir-a-ser, uma auto-compreensão ontológica préreflexiva para facilitar a compreensão/reflexão epistemológica [...]. No exercício do cuidar em enfermagem, seja individual ou coletivo, permeiam eventos de relações entre modos de ser no mundo, nas Quais seres Que cuidam e seres cuidados se entrelaçam numa dinâmica intersubjetiva recíproca e até imperceptiva. Nesse ir e vir do cuidado, pessoas (entes que cuidam) emprestam percepções, emoções, sentimentos, valores e saberes ao fenômeno (o Que aparece, pessoa Que está sendo cuidada) para fazer ver a partir de si mesmo o Que se é em si mesmo"(7).

Em sua essência, o ser-no-mundo é cura, Que aQui é utilizado do ponto de vista puramente ontológico-existencial. Sendo que a cura não indica, portanto, primordial ou exclusivamente, uma estrutura isolada do eu consigo mesmo. Cura ocupa o espaço de um duplo sentido em Que ele não significa apenas um "esforço angustiado", mas também o "cuidado" e a "dedicação"(I).

O ser que para aquilo que, em sua liberdade, pode ser para suas possibilidades mais próprias (para o projeto), é um "desempenho" da "cura". De modo igualmente originário, ela determina, porém, o modo fundamental deste ente, segundo o Qual ele está entregue ao mundo da ocupação (estar-lançado). O "duplo sentido" de "cura" significa uma constituição fundamental em sua dupla estrutura essencial de projeto lançado(1).
Cabe compreender Que a cura é parte constitutiva da natureza humana, mas Quem vai decidir é o tempo, o homem não será nada se não for o tempo/o mundo. $\mathrm{O}$ ser do homem só existe enQuanto ser no tempo. Então, o duplo sentido de cura fala da dinâmica do cuidado, de sua relação originária onde o cuidado ocupa amplos espaços estando fortemente implicado ao sentido de ser, no coexistir.

Neste mesmo sentido, o movimento constante do cuidado como ato (sentido ôntico) se manifesta na prática diária com todas as normas e rotinas estabelecidas. Porém, não se esgota aí, o cuidado também ocupa um espaço de abertura para possibilidades, como algo Que ainda pode ser desvelado. E o Que de fato faz parte da existência humana, do cuidado, só podemos conhecer na história, no modo de ser em Que predomina seu percurso temporal no mundo, naquilo Que diz respeito a sua natureza.

\section{REFLEXÕES FINAIS}

As reflexões feitas até o momento mostraram a complexidade Que envolve o cuidado humano e por meio do pensamento de Heidegger compreendemos Que conviver no cotidiano de ações da enfermagem é um desafio Que nos remete a um novo olhar para a magnitude do cuidado. No entanto, essa reordenação de olhares não Quer dizer unidirecionar as ações de cuidado somente para o prisma deste filósofo, mas sim conviver com esse pensamento buscando reflexão, e encontro, perscrutando tudo aquilo Que possa contribuir para um cuidado de enfermagem compromissado com o bem, com a ética, com o respeito ao outro.

Entendemos Que as abstrações são necessárias e podem contribuir para as concretudes do cuidado em nossos espaços de atenção à saúde. Mas, as concretudes precisam ser diariamente pensadas, refletidas, dialogadas, fundamentadas e Que se efetivem diante da complexa existência humana. Neste sentido, considerando o cuidado como algo motriz para a enfermagem, é incoerente e inconcebível permanecer realizando repetidas vezes ações que podemos considerar "robotizadas".

"O ser do ser-aí como cuidado"(I), é a abertura de mundo Que só ocorre como resultado dos existenciais conjuntamente. É o resultado desta relação, deste entrelaçamento, deste permitir que o outro se mostre e ainda de permitir Que a angústia se manifeste de maneira autêntica e inautêntica nos diferentes momentos da vida no mundo.

É esse envolvimento voluntário, sem a condição de obrigatoriedade ou modismo Que precisamos exercitar enQuanto cuidadores em saúde e enfermagem. Não podemos cuidar ou se utilizar desta palavra de forma imposta, mas procurando exercitar um modo de ser autêntico capaz de revelar nossa existência.

Nesse sentido, o cuidado é entendido como ação que vai além de procedimentos técnicos, engloba envolvimento e compromisso com o outro, tornando-se, portanto, uma ação humanizada ${ }^{(8)}$.

Entendemos que assim, essas reflexões nos ajudarão a pensar em um cuidado com liberdade e responsabilidade, Que contribua para o comprometimento com o ser humano de modo harmonioso com a natureza. 


\section{REFERÊNCIAS}

I. Heidegger M. Ser e tempo, Parte I e II. $3^{\text {a }}$ ed. Petrópolis: Vozes; 2008.

2. Safranski R. Heidegger: um mestre da Alemanha entre o bem e o mal. São Paulo: Geração Editorial; 2005.

3. Brustolin LA. A vida: dom e cuidado: Antropologia Teológica e Ética do Cuidado. Rev Trim 2006; 152(36): 44 I-60.

4. Boff L. Virtudes para um outro mundo possível: comer e beber juntos e viver em paz. Petrópolis: Vozes; 2006.

5. Nunes B. Passagem para o poético. Filosofia e poesia em Heidegger. $2^{\text {a }}$ ed. São Paulo: Ática; 1992.
6. Stein E. Prefácio à edição brasileira. In: Safranski R. Heidegger um mestre da Alemanha entre o bem e o mal. São Paulo: Geração Editorial; 2005.

7. Silva LWS, Francioni FF, Sena ELS, Carraro TE, Radünz V. O cuidado na perspectiva de Leonardo Boff, uma personalidade a ser (re) descoberta na enfermagem. Rev Bras Enferm 2005; 58(4): 47 I-5.

8. Jorge MSB, Fiúza GV, Queiroz MVO. A fenomenologia existencial como possibilidade de compreensão das vivências da gravidez em adolescente. Rev Latino-am Enfermagem 2006; 14(6): 907-14. 